\title{
Effect of Cow Urine on the Growth Characteristics of Fusarium lateritium, an Important Coffee Fungus in Zimbabwe
}

\author{
Timothy Gotora, ${ }^{1}$ Lawrence Masaka, ${ }^{2}$ and Marvelous Sungirai ${ }^{2}$ \\ ${ }^{1}$ Department of Applied Biosciences and Biotechnology, Midlands State University, Private Bag 9055, Gweru, Zimbabwe \\ ${ }^{2}$ Department of Livestock and Wildife Management, Midlands State University, Private Bag 9055, Gweru, Zimbabwe \\ Correspondence should be addressed to Lawrence Masaka; masakal@msu.ac.zw
}

Received 20 February 2014; Revised 2 July 2014; Accepted 7 July 2014; Published 23 July 2014

Academic Editor: David Clay

Copyright (c) 2014 Timothy Gotora et al. This is an open access article distributed under the Creative Commons Attribution License, which permits unrestricted use, distribution, and reproduction in any medium, provided the original work is properly cited.

\begin{abstract}
An in vitro assay was carried out to establish if cow urine at different concentrations $(500 \mu \mathrm{L} / \mathrm{mL}, 300 \mu \mathrm{L} / \mathrm{mL}, 200 \mu \mathrm{L} / \mathrm{mL}$, and $100 \mu \mathrm{L} / \mathrm{mL}$ ) can be used to control the growth of $F$. lateritium, the fungal agent causing Fusarium bark disease in coffee. The growth characteristics selected were conidial germination, germ tube length, mycelial growth rate, and sporulation. Copper oxychloride $50 \%$ W.P. was the standard, distilled water was the negative control, and undiluted cow urine was the positive control. The undiluted cow urine was most effective in inhibiting fungal growth with the rest of the cow urine concentrations showing dose dependent efficacy compared to the negative control $(P<0.01)$. Copper oxychloride had the highest efficacy of all treatments with the exception of the inhibition of mycelial growth where undiluted cow urine had higher efficacy and sporulation where efficacy was comparable to undiluted cow urine. There is potential for the use of cow urine as a means of controlling Fusarium bark disease with other advantages being availability, low cost, and limited environmental damage.
\end{abstract}

\section{Introduction}

F. lateritium Nees ex Fr. var. longum Wollew is an important ubiquitous soil borne wound phytopathogen causing Fusarium bark disease (FBD) of Coffea arabica [1]. In Zimbabwe, the disease is endemic to the Eastern coffee growing regions. In these areas, it has been reported to cause serious economic losses. Control of FBD in the region is restricted to the use of copper oxychloride based fungicides together with good agricultural practices and good hygiene practices. However, for most small scale farmers, consistent use of commercial fungicides is unsustainable as it significantly reduces the profitability of coffee farming due to the prohibitive pricing of the fungicide $[2,3]$. Another constraint to the use of copper oxychloride based fungicides is its potential environmental implications as a pollutant [4] as well as the likelihood of F. lateritium developing resistance to the fungicide [2]. In this regard, it is worthwhile for small scale coffee farmers to invest in alternative measures that are less costly and readily available and pose a limited threat to the environment.
One such alternative is cow urine. Studies, mostly concentrated in the Indian subcontinent where cow products and byproducts are held in high esteem, have shown that cow urine has bioactive properties that enable it to be a fairly potent antibacterial, antioxidant $[5,6]$, antihelminthic, anticancer [7], and antifungal agent $[8,9]$. The antifungal activity of cow urine has been confirmed against Aspergillus spp. [10] and Candida spp. [11]. When used in combination with some botanical extracts, cow urine effectively inhibited growth of Rhizoctonia spp., Fusarium spp., Sclerotinia spp., Phytophthora spp., and Colletotrichum spp. in vitro [12]. Cow urine contains phenolic acids (gallic, caffeic, ferulic, o-coumaric, cinnamic, and salicylic acids) which have antifungal characteristics [13]. However, it remains to be established whether the antifungal activity is a result of one or a combination of these phenolic acids. The purpose of this study was to determine the in vitro efficacy of cow urine in inhibiting growth of $F$. lateritium and, therefore, ascertain its potential use as a low cost control measure against FBD. 


\section{Materials and Methods}

The in vitro efficacy of cow urine was determined by observing its effect on conidial germination, germ tube length, mycelial growth rate, and conidial formation. These parameters were selected as they cover reproductive capacity and growth of infective agents which are important characteristics in disease proliferation.

2.1. Pathogen Isolation. F. lateritium Nees Fr ex. var. longum was isolated from plant material showing signs and symptoms of infection. Plant material was surface sterilized in $1 \%$ sodium hypochlorite for 30 seconds and then rinsed twice with distilled water. Small pieces of sterilized plant material were cut and left to dry on sterile filter paper on a laminar airflow cabinet for five hours. The plant pieces were, then, aseptically cultured onto Sabouraud dextrose agar (SDA) and incubated for five days at $20^{\circ} \mathrm{C}$ after which $5 \mathrm{~mm}$ discs of actively growing cultures were taken and subsequently subcultured on SDA and potato sucrose agar.

2.2. Cow Urine Collection and Preparation. Cow urine was collected from dairy cattle before milking in the morning at a local dairy farm. The urine from the individual cows was mixed to avoid variations from individual cows and stored in a refrigerator at $4^{\circ} \mathrm{C}$ prior to use. The cow urine was then mixed with distilled water to give urine concentrations of $500 \mu \mathrm{L} / \mathrm{mL}, 300 \mu \mathrm{L} / \mathrm{mL}, 200 \mu \mathrm{L} / \mathrm{mL}$, and $100 \mu \mathrm{L} / \mathrm{mL}$. Cows from which urine was collected were not under any antibiotic treatment prior to or during the period of urine collection.

\subsection{Preparation of Culture Plates. All treatments were} amended into

(1) tap water agar (TWA) for conidial germination and germ tube length assays;

(2) sabouraud dextrose agar (SDA) for mycelial growth rate;

(3) potato sucrose agar (PSA) for conidial formation assay.

All amendments were done by the addition of $1 \mathrm{~mL}$ of each treatment into $9 \mathrm{~mL}$ of warm molten nutrient media in a test tube, shaking, and then pouring into a clear glass or disposable Petri dish and left to cool and solidify before culturing. For each treatment, the procedure was replicated six times.

2.4. Conidial Germination and Germ Tube Length Assay. Conidial suspensions were made by washing plates of 10day-old cultures, grown on PSA at room temperature on the laboratory bench under natural light and darkness with $5 \mathrm{~mL}$ of Tween 80 solution $(0.1 \mathrm{~mL} / \mathrm{L}$ of sterile water). Conidial concentrations were adjusted to approximately $2 \times$ $10^{5}$ conidia/mL by haemocytometer counts. Quantities of $1 \mathrm{~mL}$ of the conidial suspensions were flushed into plates of amended TWA and incubated on the laboratory bench for 18 hours after which $1 \mathrm{~mL}$ of mercuric chloride was flushed into each of the Petri dishes to halt further conidial germination and growth of germ tubes. The proportion of germinated conidia (germ tube length greater than the length of the conidia) was determined by microscopic examination of the inoculated plates. Germ tube length was measured in microns $(\mu \mathrm{m})$ on a sample of randomly selected 10 conidia per culture plate by using a graticule.

2.5. Mycelial Growth Rate. Mycelial discs of $5 \mathrm{~mm}$ in diameter were cut from the edges of actively growing cultures from unamended plates. They were aseptically cultured at the center of amended SDA plates and the plates were incubated at room temperature on the laboratory bench for 10 days. The extent of the colony margins was marked after 2, 4, 6, 8, and 10 days to determine the growth rates in $\mathrm{mm}$ per day.

2.6. Sporulation Assay. The concentration of conidia was determined by inoculating plates of amended PSA plates with $5 \mathrm{~mm}$ mycelial discs taken from the margins of actively growing cultures on PDA. Plates were incubated at room temperature on the laboratory bench ensuring exposure to natural lighting and darkness for seven days. Conidia were harvested as was done in the mycelial growth rate assay and a single suspension per treatment was made. The conidial concentrations were then determined per $\mathrm{mL}$ of water by haemocytometer counts.

2.7. Data Analysis. All data for the conidial germination, germ tube length, mycelial growth rate, and sporulation assays were analysed using one-way analysis of variance using GENSTAT Discovery Edition 15. The response variables were conidial germination, germ tube length, mycelial growth rate, and sporulation The treatments were cow urine concentration, the standard, positive and negative controls.

\section{Results}

The effects of the treatments on selected growth characteristics of F. lateritium are summarized in Table 1. Cow urine concentration had a significant effect on all growth characteristics of $F$. lateritium measured $(P<0.01)$. The most effective treatment in controlling growth of F. lateritium was the standard (copper oxychloride 50\% W.P.) compared to the other treatments. However, there were exceptions when it came to the reduction of mycelial growth rate where undiluted cow urine was the most effective treatment. There was also no significant difference between the standard and undiluted cow urine in inhibiting sporulation with the two treatments being the most effective compared to the rest of the treatments. Of all the cow urine concentrations, the $200 \mu \mathrm{L} / \mathrm{mL}$ treatment ranked second in efficacy of inhibiting growth of $F$. lateritium with the exception of sporulation where it ranked third after undiluted cow urine, $500 \mu \mathrm{L} / \mathrm{mL}$ and $300 \mu \mathrm{L} / \mathrm{mL}$ treatments. 
TABLE 1: Effect of different concentrations of cow urine, copper oxychloride, and distilled water on the growth characteristics of $F$. lateritium.

\begin{tabular}{lcccc}
\hline Treatment & $\begin{array}{c}\text { Conidial } \\
\text { germination } \\
(\%)\end{array}$ & $\begin{array}{c}\text { Germ tube } \\
\text { length } \\
(\mu \mathrm{m})\end{array}$ & $\begin{array}{c}\text { Mycelial } \\
\text { growth rate } \\
(\mathrm{mm} / \text { day })\end{array}$ & $\begin{array}{c}\text { Sporulation } \\
(\text { conidia/mL } \\
\left.\text { water } \times 10^{3}\right)\end{array}$ \\
\hline+ ve cntrl & $10.00^{\mathrm{b}}$ & $10.70^{\mathrm{b}}$ & $0.00^{\mathrm{a}}$ & $2.75^{\mathrm{a}}$ \\
$500 \mu \mathrm{L} / \mathrm{mL}$ & $18.72^{\mathrm{c}}$ & $19.23^{\mathrm{d}}$ & $3.92^{\mathrm{e}}$ & $44.50^{\mathrm{b}}$ \\
$300 \mu \mathrm{L} / \mathrm{mL}$ & $23.33^{\mathrm{cd}}$ & $24.18^{\mathrm{e}}$ & $3.83^{\mathrm{e}}$ & $44.50^{\mathrm{b}}$ \\
$200 \mu \mathrm{L} / \mathrm{mL}$ & $13.94^{\mathrm{b}}$ & $15.05^{\mathrm{c}}$ & $2.67^{\mathrm{c}}$ & $137.25^{\mathrm{c}}$ \\
$100 \mu \mathrm{L} / \mathrm{mL}$ & $23.94^{\mathrm{d}}$ & $18.77^{\mathrm{cd}}$ & $3.38^{\mathrm{d}}$ & $152.00^{\mathrm{c}}$ \\
standard & $0.67^{\mathrm{a}}$ & $2.87^{\mathrm{a}}$ & $0.79^{\mathrm{b}}$ & $0.00^{\mathrm{a}}$ \\
- ve cntrl & $95.7^{\mathrm{e}}$ & $32.85^{\mathrm{f}}$ & $3.88^{\mathrm{e}}$ & $313.00^{\mathrm{d}}$ \\
$P$ value & $<0.01$ & $<0.01$ & $<0.01$ & $<0.01$ \\
CV\% & 15.2 & 18.5 & 14.0 & 35.3 \\
L.S.D. & 4.745 & 3.829 & 0.4313 & 35.151 \\
s.e.m. & 4.049 & 3.267 & 0.3680 & 12.368 \\
\hline
\end{tabular}

${ }^{a b}$ Means in the same column with different superscripts are significantly different. Superscripts are arranged in ascending order of the means in each column.

${ }^{*}$ Undiluted urine, ${ }^{* *}$ distilled water.

\section{Discussion}

The efficacy of cow urine and its distillates as an antifungal agent has been reported [12, 14-17]. Different authors have focused on different growth characteristics of different species of fungi as well as varying concentrations of cow urine. In some cases, cow urine has been used in combination with plant extracts $[6,12]$ or cow dung $[14]$ or as cow urine concentrate after distillation [18]. In all cases, it has been proved that cow urine can be an effective treatment and control of fungal infections. The present study sought to shed more light on the efficacy of cow urine in inhibiting growth of F. lateritium. The results have shown that, at varying concentrations of cow urine, inhibition of fungal growth is observed with the efficacy being largely dependent on the cow urine concentration. The efficacy of cow urine in controlling conidial germination agrees with the findings of Payne et al. [19] though there are some differences in experimental design that may have had a bearing on results obtained. In their study, Payne et al. [19] used the cow urine in combination with some botanical extracts which makes it impossible to attribute the observed reduction in conidial germination to cow urine alone, whereas the present study does clarify cow urine's efficacy. In an in vitro assessment of the efficacy of cow urine distillates, Deshmukh et al. [20] found that germ tube lengths of Aspergillus spp. and Mucor spp. were significantly reduced by treatment with cow urine distillates compared to the control. This finding is consistent with the present study where lower germ tube lengths were observed in all treatments with cow urine although we did not subject the cow urine to distillation prior to use.

The observed reduction in mycelial growth rate in the present study concurs with the findings of Alam et al. [15] who reported a reduction in mycelial growth of Sclerotinia sclerotiorum, a fungi causing Sclerotinia rot in cucumbers, when the fungi was incubated in cow urine PDA for six days. The fact that undiluted cow urine resulted in mycelial growth rates of zero for the period under study while the copper oxychloride treatment had some growth might be an indication of the development of fungicide resistance by F. lateritium to some extent. In an experiment using the poisoned food technique to determine efficacy of cow urine distillate in inhibition of growth of Aspergillus spp., Rhizopus spp., and Fusarium oxysporum, it was observed that cow urine restricted growth of Aspergillus spp. and Rhizopus spp. and was lethal to F. oxysporum [21]. It can be hypothesized that the lethality of cow urine is dependent on fungi species since the current study also revealed a lethal effect of cow urine on F. lateritium seen as the absence of mycelial growth in fungi treated with undiluted cow urine. Another factor that might affect the potency of cow urine is the management of the cows. It has been reported that urine from pasture fed cows appeared to be more effective than that from barn fed cows [20]. In the current study, sporulation was observed to be inhibited by all cow urine concentrations in a dose dependent manner; this is in agreement with the findings of Deshmukh et al. [20]. The effect of cow urine on sporulation is the only instance in the current study where efficacy was entirely dose dependent. The other growth characteristics, conidial germination, germ tube length, and mycelial growth rate, had peculiar results in that the $200 \mu \mathrm{L} / \mathrm{mL}$ treatment had higher efficacy in inhibiting growth compared to treatments with a higher urine concentration $(300 \mu \mathrm{L} / \mathrm{mL}$ and $500 \mu \mathrm{L} / \mathrm{mL})$ but not undiluted urine. This finding contradicts those of other authors who observed a strictly dose dependent response [10, $17,21-23]$. It is unclear at this point why a lower concentration appeared to be more effective compared to higher urine concentrations.

When used as a control against fungal infections, cow urine can have a dual role as it has been reported that, due to its nitrogen content, it can enhance plant growth $[21,24]$.

\section{Conclusions}

The results of the current in vitro study reveal that there is potential for the use of cow urine as a control measure against FBD in coffee. Cow urine has the advantages of being easily accessible to small scale coffee farmers who normally have small herds of cattle as they practice mixed farming. The use of cow urine poses a much smaller threat to the environment as it can be broken down and the nitrogen composition of urine may also improve soil quality in areas were nitrogen is deficient. There is still a need to conduct in vivo trials to ascertain cow urine's efficacy in the control of $F$. lateritium. This is necessitated by the fact that laboratory conditions can be more tightly controlled, whereas field conditions are constantly fluctuating, and this may lead to differences in the anticipated performance of cow urine as a control measure.

\section{Conflict of Interests}

The authors declare that there is no conflict of interests regarding the publication of this paper. 


\section{Acknowledgments}

The authors would like to thank Dr. Dumisani Kutwayo and staff at the Coffee Research Station for the provision of laboratory space as well as the late Mr. Chimbira for assisting with the conduction of the microbiological assays.

\section{References}

[1] R. C. Ploetz, "Fusarium-induced diseases of tropical, perennial crops," Phytopathology, vol. 96, no. 6, pp. 648-652, 2006.

[2] M. Handiseni, S. Julia, V. B. Ogunlela, and I. Koomen, "Reduced frequency of fungicide application in the management of Paprika (Capsicum anuum L.) diseases under dryland conditions in Zimbabwe," Journal of Plant Protection Research, vol. 47, no. 1, pp. 19-28, 2007.

[3] A. Mafusire, A. O. Salami, A. B. Kamara, and F. E. Lawson, "Coffee production in Africa and the global market situation," in Commodity Market Brief, M. Ncube, C. L. Lufumpa, and L. Ndikumana, Eds., pp. 1-9, The African Development Bank Group, 2010.

[4] L. Kiaune and N. Singhasemanon, "Pesticidal copper (I) oxide: environmental fate and aquatic toxicity," Reviews of Environmental Contamination and Toxicology, vol. 213, pp. 1-26, 2011.

[5] E. Jarald, S. Edwin, V. Tiwari, R. Garg, and E. Toppo, "Antioxidant and antimicrobial activities of cow urine," Global Journal of Pharmacology, vol. 2, no. 2, pp. 20-22, 2008.

[6] H. Yadav, M. Yadav, S. Jain et al., "Antimicrobial property of a herbal preparation containing Dalbergia sissoo and Datura Stramonium with cow urine against pathogenic bacteria," International Journal of Immunopathology and Pharmacology, vol. 21, no. 4, pp. 1013-1020, 2008.

[7] N. K. Jain, V. B. Gupta, R. Garg, and N. Silawat, "Efficacy of cow urine therapy on various cancer patients in Mandsaur District, India-a survey," International Journal of Green Pharmacy, vol. 4, no. 1, pp. 29-35, 2010.

[8] H. S. R. Patil, H. K. Makari, H. Gurumurthy et al., "Effect of cow urine on fungal spore germination," Biotechnology: An Indian Journal, vol. 1, no. 3, pp. 130-134, 2007.

[9] T. R. Prashith Kekuda, B. C. Nishanth, S. V. Praveen Kumar, D. Kamal, M. Sandeep, and H. K. Megharaj, "Cow urine concentrate: a potent agent with antimicrobial and anthelmintic activity," Journal of Pharmacy Research, vol. 3, no. 5, pp. 10251027, 2010.

[10] A. Sathasivam, M. Muthuselvam, and R. Rajendran, "Antimicrobial activities of cow urine distillate against some clinical pathogens," Global Journal of Pharmacology, vol. 4, no. 1, pp. 4144, 2010.

[11] R. Rana and S. De, "In vitro antimicrobial screening of cow urine-a potential natural antimicrobial agent," International Journal of Bioassays, vol. 2, no. 2, pp. 436-439, 2013.

[12] A. Ashlesha, "Antifungal activity of distillates of cow urine and botanicals," Plant Disease Research, vol. 26, no. 2, pp. 163-164, 2011.

[13] U. P. Singh, S. Maurya, A. Singh, G. Nath, and M. Singh, "Antimicrobial efficacy, disease inhibition and phenolic acidinducing potential of chloroform fraction of cow urine," Archives of Phytopathology and Plant Protection, vol. 45, no. 13, pp. 1546-1557, 2012.

[14] R. W. Payne et al., GenStat forWindows, VSN International, Hemel Hempstead, UK, 2012.
[15] N. Akhter, M. N. Vivek, M. Manasa, Y. Kambar, A. S. Noor Nawaz, and H. L. Raghavendra, "Inhibitory effect of different plant extracts, cow dung and cow urine on conidial germination of Bipolaris sorokiniana," Journal of Biosciences, vol. 14, pp. 8792, 2006.

[16] S. Alam, M. R. Islam, M. A. Sarkar et al., "In vitro inhibition effect of plant extracts, urine, fertilizers and fungicides on stem rot pathogen of Sclerotium rolfsii," Mycobiology, vol. 32, no. 3, pp. 128-133, 2004.

[17] A. B. Basak and M. W. Lee, "Efficacy of cow dung for controlling root rot and Fusarium wilt diseases of cucumber plant," in Proceedings of the Korean Society of Plant Pathology Annual Meeting and International Conference, vol. 30, p. 49, Kyongju, Republic of Korea.

[18] A. B. Basak, M. W. Lee, and T. S. Lee, "Inhibitive activity of cow urine and cow dung against sclerotinia sclerotiorum of cucumber," Mycobiology, vol. 30, no. 3, pp. 175-179, 2002.

[19] S. Khanuja, S. Kumar, A. Shasany et al., Use of Bioreactive Fraction from Cow Urine Distillate ("Go Mutra") as a Bioenhancer of Anti-Infective, Anti-Cancer Agents and Nutrients, U.S.P. Office, Council of Scientific and Industrial Research, New Delhi, India, 2007.

[20] R. Vijayalakshmi and V. T. K. Saranya, "Effect of "Go-Mutra" on plant growth and its antifungal and antibacterial activity," Journal of Herbal Science and Technology, vol. 6, no. 6, pp. 611, 2010.

[21] S. S. Deshmukh, S. S. Rajgure, and S. P. Ingole, "Antifungal activity of cow urine," IOSR Journal of Pharmacy, vol. 2, no. 5, pp. 27-30, 2012.

[22] T. R. P. Kekuda, R. Kavya, R. M. Shrungashree, and S. V. Suchitra, "In Vitro studies on antifungal activity of cow urine distillate against fungi causing opportunistic infections," Biotechnology: An Indian Journal, vol. 2, no. 1, pp. 62-64, 2008.

[23] S. Kumar, "Analysis of cow's urine for detection of lipase activity and anti-microbial properties," Journal of Pharmacy and Biological Sciences, vol. 7, no. 1, pp. 1-8, 2013.

[24] N. L. C. de Oliveira, M. Puiatti, R. H. S. Santos, P. R. Cecon, and P. H. R. Rodrigues, "Soil and leaf fertilization of lettuce crop with cow urine," Horticultura Brasileira, vol. 27, no. 4, pp. 431437, 2009. 


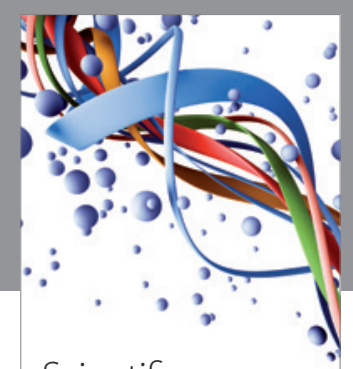

Scientifica
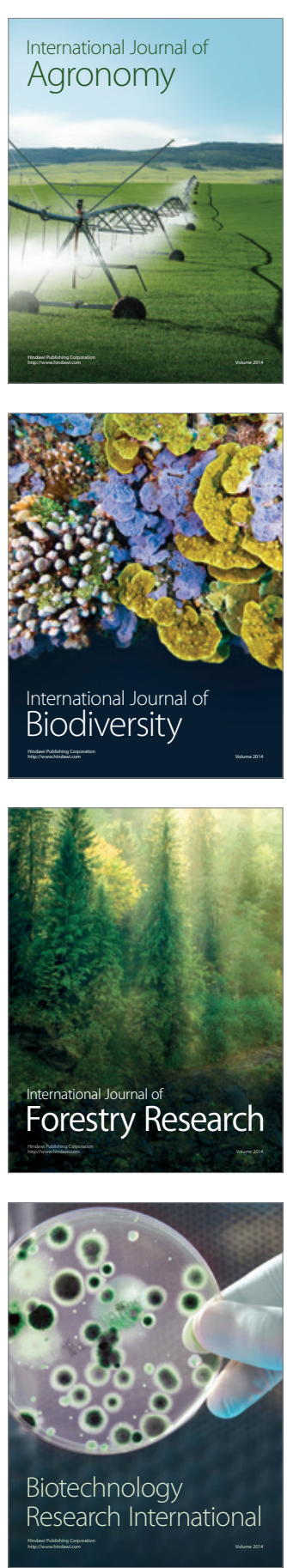
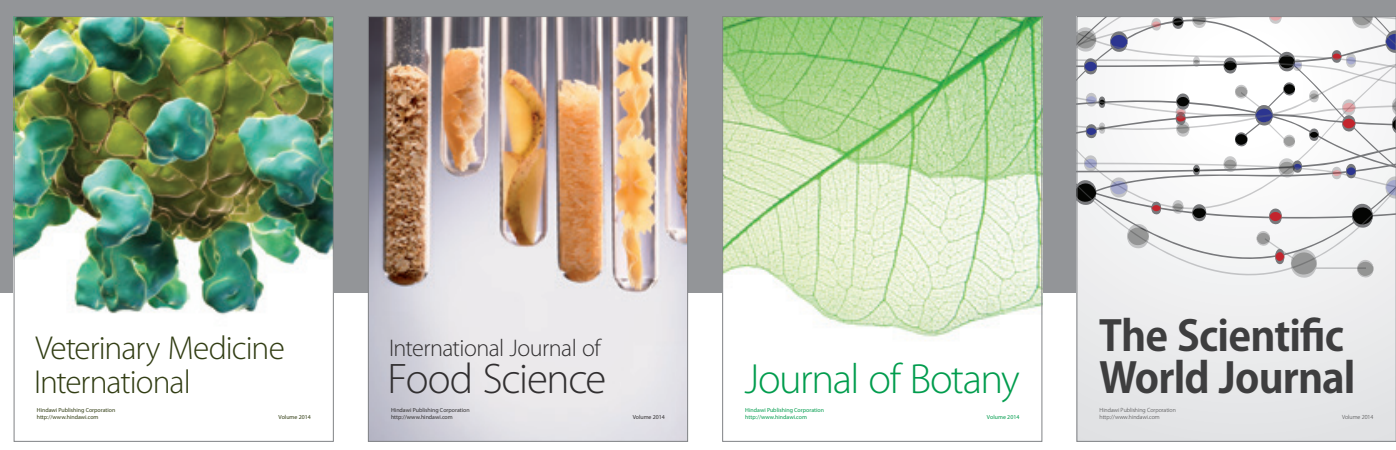

The Scientific World Journal
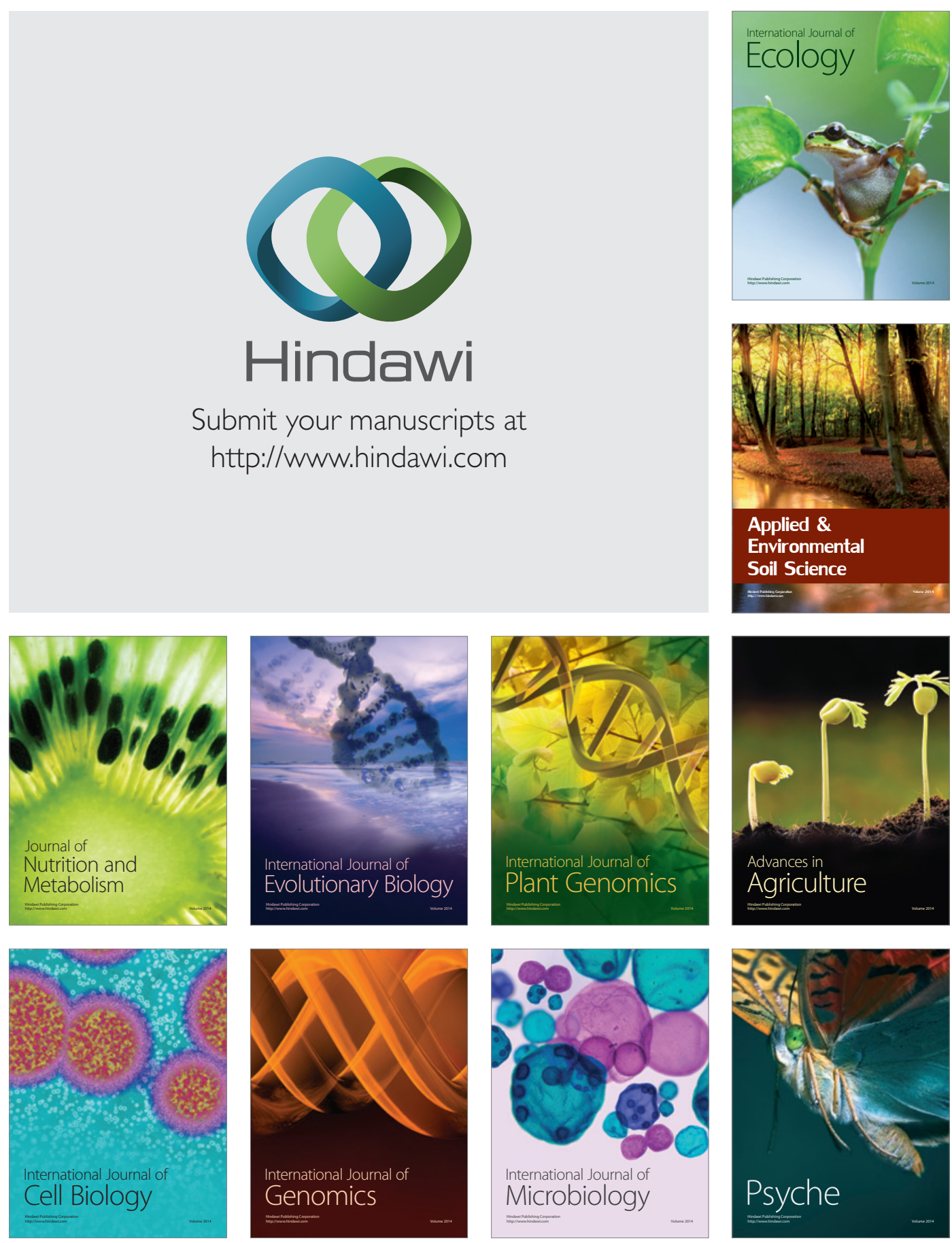